\title{
Serum Albumin Variants in New Guinea Indigenes
}

\author{
L. R. Weitkamp, D. C. Shreffler and J. J. SaAve \\ Department of Human Genetics, University of Michigan Medical School, Ann Arbor, \\ MI and Central Malaria Laboratory, Port Moresby
}

Four types of rapidly migrating and four types of slowly migrating variants of human serum albumin have been distinguished by starch gel electrophoresis [3]. Three of these were found in American Indians and the rest in Caucasians. As one adjunct to surveys undertaken for the purpose of malaria control, specimens from 724 individuals from 44 widely scattered indigenous villages in the Australian territories of Papua and New Guinea were examined in two starch gel electrophoretic systems (indicated in the legend of Figure 2) for variants of serum albumin: one rapidly migrating and one slowly migrating type of variant were observed.

The electrophoretic pattern of the rapidly migrating variant has been previously reported [3]. This variant has now been found in residents of three widely separated New Guinea villages : in two of 35 people from a village $\left(6^{\circ} 10^{\prime} \mathrm{S}\right.$ and $\left.146^{\circ} 12^{\prime} \mathrm{E}\right)$ in Marksham Valley in the Eastern Highlands, in one of 45 people from a village $\left(8^{\circ} 38^{\prime} \mathrm{S}\right.$ and $\left.146^{\circ} 12^{\prime} \mathrm{E}\right)$ near Papondetta in the southeastern peninsula and in four of 31 people from Rossel Island $\left(11^{\circ} 21^{\prime} \mathrm{S}\right.$ and $\left.154^{\circ} 16^{\prime} \mathrm{E}\right)$ in the Louisade Archipelago. An additional 12 individuals with the variant were identified during a subsequent investigation of relatives of the probands from Rossel Island, and the usual, autosomal, co-dominant pattern of inheritance observed (fig. 1). Since the sera were examined in two starch gel electrophoretic systems which are capable of detecting a variety of human albumin variants, it seems most likely that the rapidly migrating variant, despite its ascertainment in widely separated regions of New Guinea, is in each case the same. Although the individuals in this survey were not unrelated and hence no estimate of gene frequency can be made, the appearance of the variant in a few individuals from three widely separated areas 


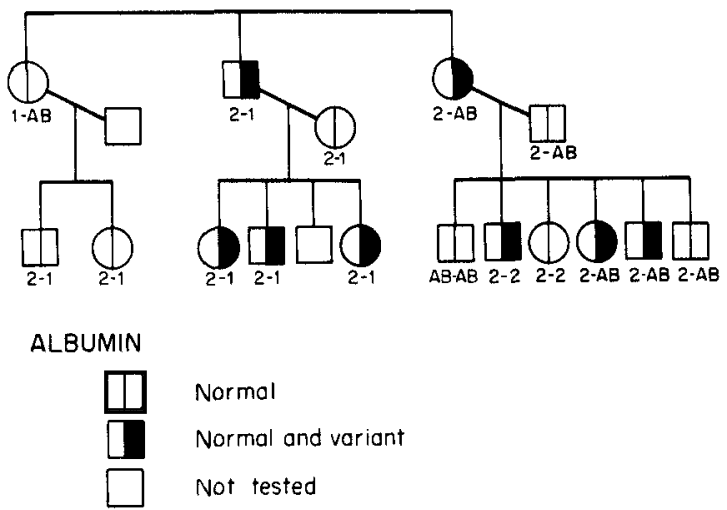

Fig. 1. Pedigree of a family illustrating the pattern of inheritance of albumin New Guinea and the segregation of alleles at the albumin and $\mathrm{Gc}$ loci. Squares designate males, circles females. Gc phenotypes are indicated below the pedigree symbols.

suggests it may occur at a low but polymorphic frequency. Despite the fact that this variant has been previously found to be electrophoretically indistinguishable from a variant in a Greek family and a variant in a British family [3], we propose to identify it separately as albumin New Guinea until the structural basis for these variants is determined.

Close genetic linkage between loci for serum albumin and Group Specific Component (Gc) has now been demonstrated using three different albumin variants $[2,4,5]$ and the two common $\mathrm{Gc}$ alleles, $\mathrm{Gc}^{1}$ and $\mathrm{Gc}^{2}$. For the three different variants there were approximately 1 recombinant and 66 non-recombinants, 1 recombinant and 18 nonrecombinants, 0 recombinants and 17 non-recombinants. The only pedigree which was informative for linkage of the locus identified by Albumin New Guinea and the Gc locus is shown in figure 1. The correctness of the relationships of individuals in this pedigree is problematic especially because of the difficulties in communicating with a primitive people, but the haptoglobin as well as the $\mathrm{Gc}$ and albumin phenotypes were consistent with the historical data. The Gc Aborigine ( $\mathrm{Gc} \mathrm{Ab}$ ) variant which occurs in this family is produced by an allele at the Gc locus and is not unexpected since it has a frequency of about $5 \%$ in this population [1]; it was identified by immunoelectrophoretic comparison with a sample of Aborigine variant generously supplied by Professor A. G. Bearn. From the 
pedigree of the family it is clear that there is at least one recombinant. Although the family provides little evidence for linkage, a finding of only one recombinant is not inconsistent with the a priori expectation that albumin New Guinea is produced by an allele at the same locus as other albumin variants.

The electrophoretic pattern of the slowly migrating variant is shown in figure 2 . In the starch gel, $\mathrm{pH} 6.9$ system, this variant is indistinguishable from normal. However, in the $\mathrm{pH} 5.0$ system, it is recognized as an unusually broad band of albumin, perhaps resulting from inadequate separation of normal and variant albumin. It was originally identified in two of eight individuals from the village of Uinba $\left(5^{\circ} 59^{\prime} \mathrm{S}\right.$ and $\left.144^{\circ} 14^{\prime} \mathrm{E}\right)$. In a later survey, also made for the purpose of malaria control, another sample from one of the probands was obtained and found to have the same pattern; two other examples of the variant pattern were found in an additional 74 individuals.

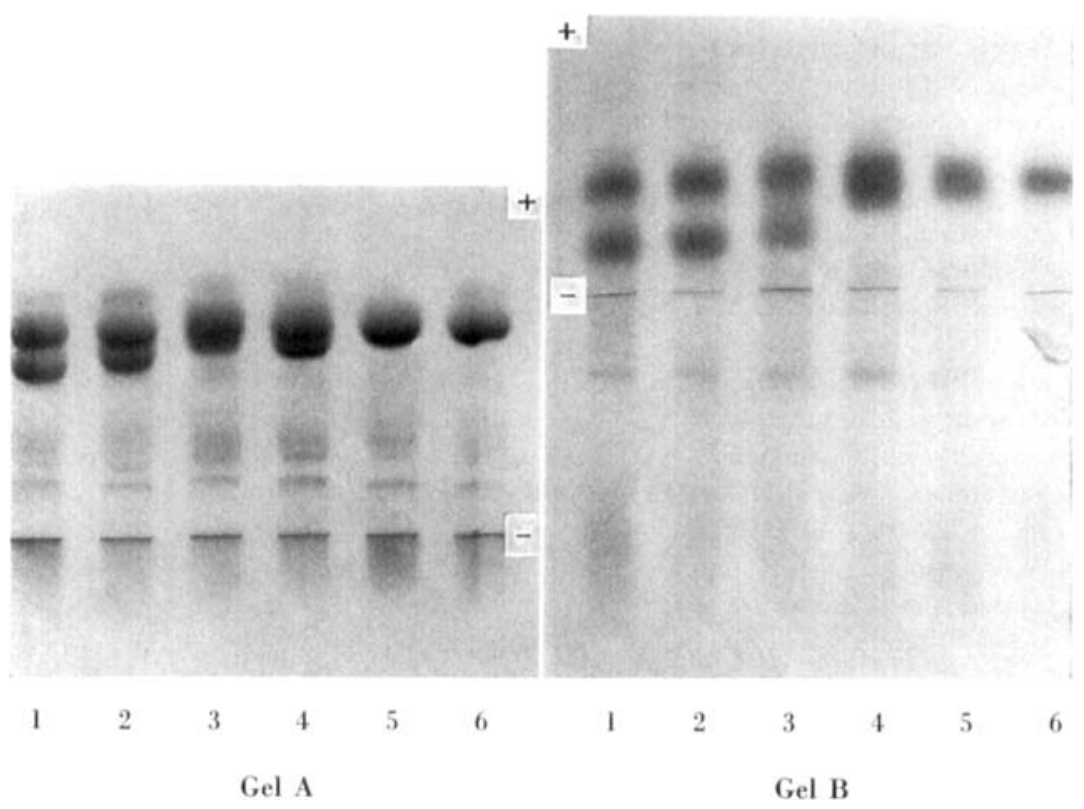

Fig. 2. Albumin Uinba. Comparative vertical starch gel electrophoresis using the four types of slowly migrating albumin variants and electrophoretic conditions detailed in WeitKamp et al. [3]. Gel A: Electrophoresis for $6 \mathrm{~h}$ in the tris-EDTAborate system, pH 6.9; Gel B: Electrophoresis for $19 \mathrm{~h}$ in the sodium acetate-EDTA system, pH 5.0 (Lot 354, Electro Starch Co., Madison, Wis.). Position 1, Family 10; 2, Family 24; 3, Family 11; 4, Family 26, 5, Albumin Uinba; 6, normal albumin. 
Thus, there were four instances of the variant in 82 individuals living in one village. One individual with the variant phenotype had a normal offspring, but no other relevant pedigree information is available. In analogy with previous data on albumin variants, however, these individuals are probably heterozygotes for a rare structural albumin variant. We propose to identify it provisionally as albumin Uinba.

\section{Acknowledgements}

We thank Mrs. K. Ryan, Mrs. S. Niedenhuben and Mr. J. McCormick for technical assistance. This work was supported by US Atomic Energy Commission Contract AEC AT(11-1)-1552.

\section{References}

1. Cleve, H.; Kink, R. L.; Parker, W. C.; Bearn, A. G.; Schacht, L. E.; Kueinman, H. and HorsfalL, W. R.: Two genetic variants of the Group-Specific Component of human serum: Ge Chippewa and Ge Aborigine. Amer. J. hum. Genet. 15: 368-379 (1963).

2. Kaarsalo, E.; Melartin, L. and Buumberg, B. S.: Autosomal linkage between the albumin and Gc loci in humans. Science 158: 123-125 (1967).

3. Weitkamp, L. R.; Franglen, G.; Rokala, D. A.; Polesky, H. F.; Simpson, N. E.; Sunderman, F. W., Jr.; Bell, H. E.; SaAve, J.; Lisker, R. and Bohrs, S. W. : An electrophoretic comparison of human serum albumin variants: eight distinguishable types. Hum. Hered. 19: 159-169 (1969).

4. Weitkamp, L. R.; Robson, E. B.; Shrefflen, D. C. and Conney, G.: An unusual serum albumin variant: Further data on genetic linkage between loci for human serum albumin and Group Specific Component (Gc). Amer. J. hum. Genet. 20: 392-397 (1968).

5. Weitkamp, L. R.; Rucknagez, D. L. and Gershowitz, H.: Genetic linkage between loci for human serum albumin and Group Specific Component (Gc). Amer. J. Hum. Genet. 18: 559-571 (1966).

Authors' addresses: Dr. Lowell R. Weitkamp and Dr. Donald C. Shreffler, Department of Human Genetics, University of Michigan Medical School, 1133 East Catherine Street, Ann Arbor, MI 48104(USA); Dr. JAN J. SaAve, Box 2119, Konedobu, Port Moresby (New Guinea). 